\title{
Attitudes towards the male contraceptive pill in men and women in casual and stable sexual relationships
}

\author{
Judith Eberhardt, Anna van Wersch, Neil Meikle
}

\begin{abstract}
Background and methodology Men's and women's attitudes towards the male contraceptive pill and their trust in the effective use of the male pill were investigated, as well as the associated variables of reported health behaviours, perceived self-efficacy and type of sexual relationship, using a questionnaire survey.
\end{abstract}

Results Although both sexes had a favourable attitude towards the male pill, females had a more positive attitude than men. Conversely, women had less trust that men would use the male pill effectively. Males in stable sexual relationships were more positive about the male pill than those in casual sexual relationships. Gender, relationship type and trust in the effective use of the male pill reliably predicted attitude towards the male pill. High perceived self-efficacy was related to engaging in more health behaviours, and in men a positive association between

\section{Introduction}

Traditionally, contraception has been the responsibility of women, hence their access to a variety of options. ${ }^{1}$ For men, there is the condom; other options are vasectomy or natural methods, but these are less reliable. ${ }^{2}$ Family planning is restricted by the lack of reliable and reversible methods available to men.

Contraceptive failure has further-reaching consequences for women than for men. ${ }^{3}$ Even if effective male hormonal contraception (MHC) were to be made available, contradictory findings suggest that men would 4 or would not ${ }^{5}$ take over the responsibility for fertility control and could or could not be trusted to do so. Moreover, it has been postulated that the resources currently being directed at new contraceptives for men would be better spent making existing methods more widely available. 6

Men only use contraception in around one-third of heterosexual partnerships. ${ }^{7,8}$ Some findings indicated that the majority of men seem to believe that men and women share equal responsibility for the decisions about contraception. ${ }^{9}$ However, social research has repeatedly highlighted the contradictory role of men in fertility regulation: although many men believe that the responsibility for contraception should be shared, in practice many prefer not to use any. ${ }^{10,11}$ Men are not seen as able to regulate their own fertility, and are likely to reject responsibility when asked. ${ }^{12}$ It has been asserted that it is part of the image of male masculinity to exhibit fertility rather than preventing it. ${ }^{12-14}$ Similarly attributed to the traditional masculine role are men's reluctant attitudes towards taking care of their own health because that would be a sign of weakness. ${ }^{15}$ Compared to women, men have

School of Social Sciences and Law, University of Teesside,

Middlesbrough, UK

Judith Eberhardt, BSc, MSc, Research Fellow

Anna van Wersch, MSc, PhD, Professor

Neil Meikle, BSc, MA, Psychology Technician

Correspondence to: Professor Anna van Wersch, Psychological Therapies Clinic, School of Social Sciences and Law, University of Teesside, Middlesbrough, Tees Valley TS1 3BA, UK.

E-mail: a.van-wersch@tees.ac.uk health behaviours and attitude towards the male pill has been found.

Discussion and conclusions A positive attitude towards the male pill does not automatically imply that the individual is confident about its effective use. Once the male pill is widely available, promotional campaigns could target not only men but also their female partners, as the latter tend to come into contact with health services more frequently. In order to increase confidence in effective implementation, a variety of presentations of the male pill should be made available in line with individual needs and lifestyles.

Keywords gender differences, health behaviours, hormonal contraception, male contraception, male pill

J Fam Plann Reprod Health Care 2009; 35(3): 161-165 (Accepted 5 February 2009)

\section{Key message points}

- Both men and women generally had a favourable attitude towards the male contraceptive pill.

- Women had a more positive attitude towards the male pill than men, but had less trust that it would be used effectively by men.

- Men in stable sexual relationships, in particular, had a more positive attitude towards the male pill than those in casual sexual relationships.

less regular contact with health care professionals 15,16 and are less likely to seek preventive reproductive and sexual health information and contraceptives. ${ }^{15,17}$

Many women, conversely, endure adverse side effects from the contraceptives they have chosen to employ, ${ }^{18-21}$ and use services that are usually provided as part of maternal and child health care. ${ }^{22,23}$ Some have indicated that they want their male partners to play a bigger role in selecting the method of contraception. 5,24

MHC would not only be welcomed by women but also by men. A study by Brooks ${ }^{25}$ demonstrated that the male pill may receive considerable uptake, with most male respondents ranking it as their first choice of contraception, although over $70 \%$ of those questioned indicated that they would not tolerate any possible side effects. Similar findings were reported in other studies. ${ }^{26,27}$

Development of MHC compared to female hormonal contraceptives has been slow. Although research into MHC has been ongoing since the early 1970s, a male contraceptive pill has yet to be implemented. This delay has been attributed to the fact that reproductive responsibility has traditionally fallen to women and there seems to be a reluctance to delegate part of this responsibility to men, as well as greater concerns about potential side effects. ${ }^{13}$

To date, studies on MHC have mainly focused on males. Although women's confidence in the effective use of MHC has been previously studied, 4,5,28 there is a lack of studies investigating how this trust impacts upon their attitudes towards the male pill.

Differences in health behaviours (such as taking vitamin supplements or going for regular medical checkups) seem to 
be important in relation to MHC. Regarding their health, men are known to take less care (as a trait of masculinity) or to overly take care (being scared of any unexpected bodily change such as possible side effects). 13

Another mediating factor, studied by Reis et al. ${ }^{29}$ is self-efficacy: the belief that one is capable of making the right decisions that will lead to expected outcomes. ${ }^{30}$ High perceived self-efficacy has been found to result in a more effective use of contraceptives in heterosexual females. 31 However, its role regarding attitudes towards the male pill and possible gender differences have thus far not been examined.

Condoms tend to be used in casual sexual relationships ${ }^{32}$ but whether use of the contraceptive pill is more closely linked to stable sexual relationships has controversial findings. 33,34 There is a lack of studies investigating this, particularly in relation to the male pill. Consequently, the current study aimed to investigate the associations and differences between men's and women's attitudes towards the male contraceptive pill and the identified relevant factors, such as trust in the effective use of the male pill, engagement in healthy behaviours, perceived self-efficacy, and type of sexual relationship.

\section{Methods \\ Sample}

A power analysis was carried out using the software package Power Analysis and Sample Size Software $(\mathrm{PASS})^{35}$ and revealed that a sample size of $n=206$ achieves $80 \%$ power to detect an $\mathrm{R}^{2}$ of 0.5 attributed to six independent variables using an $F$-test with a significance level $(p)$ of 0.05 . An opportunistic sample of $n=380$ in the North East of England completed the Male Contraceptive Pill Inventory (MCPI), which was designed specifically for this study. After data collection, male and female participants were matched exactly according to their age and relationship type, resulting in 110 pairs of matched male and female participants $(n=220)$. Their ages ranged from 18 to 50 (mean: 23.53) years. The matching procedure was carried out because the opportunity sample had yielded a larger number of females than males as well as an overrepresentation of younger age groups; matching ensured that the sexes as well as age groups were equally represented.

\section{Instruments}

The inventory consisted of four parts: (1) demographics: age, gender, type of sexual relation (casual or stable); (2) attitudes towards the Male Contraception Pill scale questionnaire (AMCP); (3) Reported Health Behaviours Checklist (RHBC) ${ }^{36}$ and (4) Generalized Self-Efficacy Scale (GSES). ${ }^{37}$ The 21 items of the AMCP were constructed on the basis on the results of an analysis of male and female commentary on the male pill from two websites (http://news.bbc.co.uk/1/hi/talking_point/653601. stm; http://www.malehealth.co.uk/userpage1.cfm?item_id $=1436$ ) and the findings from relevant literature. The answer format is a four-point Likert scale, ranging from 1 ("not true at all") to 4 ("exactly true"). The RHBC is an existing scale of 21 items validated in studies with various samples. ${ }^{38}$ This instrument assesses compliance with 21 health-promoting actions. The answer format is a six-point Likert scale, ranging from 1 ("never") to 6 ("always"). The GSES is a 10-item scale, translated into 30 languages and validated in many studies with hundred of thousands of participants ${ }^{39}$ with the answer format of a four-point Likert scale ranging from 1 ("not true at all") to 4 ("exactly true"). This scale is used to assess self-beliefs to cope with a range of complex demands in life, particularly the belief that one's own actions are accountable for favourable outcomes.

\section{Procedure}

People were randomly approached at various locations in the North East of England and asked to collaborate in a study examining attitudes towards the male contraceptive pill. If interested, the aims and procedures were explained and anonymity guaranteed. The questionnaire and a pen were provided, and individuals were shown a quiet place to sit to answer the questions on their own. Completion took between 10 and 15 minutes. Completed questionnaires were collected and participants thanked for their collaboration.

\section{Analyses}

The psychometric properties of the scales of the MCPI were explored using the Statistical Package for the Social Sciences (SPSS) (SPSS Inc., Chicago, IL, USA) after the data were entered into a computer file. Items indicating a

Table 1 Factor loadings for the selected Male Contraceptive Pill Inventory (MCPI) items

\begin{tabular}{|c|c|c|}
\hline Item & $\begin{array}{l}\text { Factor I (attitude towards the } \\
\text { male pill) loadinga }\end{array}$ & $\begin{array}{l}\text { Factor II (trust in men's effective use } \\
\text { of the male pill) loadinga }\end{array}$ \\
\hline $\begin{array}{l}\text { As a man/woman I am trustworthy to use the male } \\
\text { or female contraception pill }\end{array}$ & 0.797 & \\
\hline $\begin{array}{l}\text { The male pill should be made available on the } \\
\text { National Health Service (NHS) }\end{array}$ & 0.679 & \\
\hline $\begin{array}{l}\text { I will make sure that I, or my male partner, will use } \\
\text { the male pill }\end{array}$ & 0.434 & \\
\hline $\begin{array}{l}\text { If the male pill will be made available by the health } \\
\text { authorities then men will trust that the pill is safe }\end{array}$ & 0.638 & \\
\hline I am glad the male pill will be available shortly & 0.618 & \\
\hline $\begin{array}{l}\text { I will not support the use of the male pill because } \\
\text { side effects in the long term are unknown }(R)\end{array}$ & 0.479 & \\
\hline $\begin{array}{l}\text { Females are more trustworthy in using the pill than } \\
\text { males }(R)\end{array}$ & & 0.815 \\
\hline Men cannot be trusted to use the male pill (R) & & 0.718 \\
\hline $\begin{array}{l}\text { Women are more trustworthy than men when they } \\
\text { say they are using the pill }(R)\end{array}$ & & 0.776 \\
\hline
\end{tabular}

aExtraction method: principal components. R, reversed item in scale's total score. 
Table 2 Significant Pearson/Spearman correlation coefficients for the whole sample, as well as male and female participants

\begin{tabular}{|c|c|c|c|c|c|}
\hline Predictor & Age & Gender & Relationship type & $\begin{array}{l}\text { Reported health } \\
\text { behaviours }\end{array}$ & $\begin{array}{l}\text { Trust in men's } \\
\text { effective use of } \\
\text { the male pill }\end{array}$ \\
\hline Attitude towards male pill & & $0.300^{* *}$ & $-0.185^{\star \star}\left(-0.223^{\star}\right.$ men only) & $0.213^{\star}$ men only & \\
\hline Self-efficacy & $0.286^{* *}$ women only & & $-0.205^{\star}$ men only & $\begin{array}{l}0.439^{* *}\left(0.418^{* *} \text { men, }\right. \\
\left.0.561^{* *} \text { women }\right)\end{array}$ & \\
\hline Age & & & $-0.221^{\star *}$ & & \\
\hline Relationship type & $\begin{array}{l}-0.237^{\star *} \\
\left(-0.238^{*} \text { women, }\right. \\
\left.-0.238^{\star} \text { men }\right)\end{array}$ & & & & \\
\hline Gender & & & & & $-0.225^{\star *}$ \\
\hline
\end{tabular}

${ }^{*} p<0.05,{ }^{* *} p<0.01$.

negative attitude towards the male pill and low trust in men were reversed (R). A factor analysis using principal components as the method of extraction and direct oblimin rotation yielded a six-factor solution for the AMCP; oblique rotation was chosen because there were theoretical grounds to assume that the factors were correlated. ${ }^{40}$ This was further confirmed through oblique rotation producing a moderately correlated factor structure. While all six factors produced by the factor solution had eigenvalues higher than 1 , factor 1 and 2 had eigenvalues of 3.143 (explaining $15 \%$ of the variance) and 2.459 (explaining $11.7 \%$ of the variance), respectively. Subsequent analyses identified these factors to be of high reliability (Table 1). Together they explained $26.68 \%$ of the total variability, and were labelled "attitude towards the male pill" (Cronbach's $\alpha=0.71$ ) and "trust in men's effective use of the male pill" (Cronbach's $\alpha=0.76$ ), the latter indicating the individual's level of confidence that the male pill would be used correctly. The internal consistency of both factors was further tested by conducting multiple regression analyses, using factor scores as the outcome variable and factor components as prediction variables. Both analyses indicated high internal consistency for both factor I (attitude) and factor II (trust) with an adjusted $\mathrm{R}^{2}=0.96$ and 0.94 , respectively.

Internal consistency of both the RHBC and the GSES was excellent, with a Cronbach's $\alpha$ of 0.73 for the RHBC and 0.85 for the GSES.

Missing data were dealt with by instructing SPSS to exclude cases pair-wise, according to recommendations by Field. 40

After calculating mean scores for the RHBC and GSES, Pearson correlation coefficients were calculated for these variables in relation to the factors attitude towards the male pill and trust in men's effective use of the male pill. For the discrete variables age and relationship type, associations were calculated using Spearman correlation coefficients. Mann-Whitney tests were performed to determine any significant differences between males and females.

Following the screening of the data for normality, collinearity and homoscedasticity, a multiple regression analysis was performed in order to predict attitude towards the male pill as an outcome variable from a set of six predictor variables: self-efficacy, reported health behaviours, relationship type, trust in men's effective use of the male pill, age and gender.

\section{Results}

Mann-Whitney tests showed significant gender differences on attitude towards the male pill $(U=2922, p<0.0001)$, with females in general being more positive; and on trust in men's effective use of the male pill $(U=3440, p<0.0001)$, with males in general displaying more trust in themselves than females in them.

The overall attitude towards the male pill was moderately positive (mean $=2.86, \mathrm{SD}=0.599, n=220$ ), while trust in men's effective use of the male pill was lower (mean $=2.245, \mathrm{SD}=0.754, n=220)($ scored $1-4)$.

Separate correlations for men and women (Table 2) revealed that the association between reported health behaviours and perceived self-efficacy was strong in both women $(r=0.561, p<0.01)$ and men $(r=0.418, p<0.01)$, showing that participants who engaged in health behaviours also tended to have higher self-efficacy. In men only, a positive attitude towards the male pill was associated with engaging in reported health behaviours ( $r$ $=0.213, p<0.05)$. Men in stable relations were more likely to have high self-efficacy $(r=-0.205, p<0.05)$ and a more positive attitude towards the male pill $(r=-0.223, p<0.05)$.

The multiple regression model, assessing differences in attitudes more specifically by looking at the individual contributions of the predictor variables while controlling for the others, had an adjusted $\mathrm{R}^{2}$ of 0.16 , indicating that the regression model explained $16 \%$ of variance (Table 3 ). The overall relationship between predictors and outcome was significant $[F(6,213)=6.858, p<0.0001]$. With other variables held constant, gender significantly predicted the attitude towards the male pill $(\alpha=0.737, p<0.0001)$, with attitude increasing by 0.737 points for females compared to males, as did relationship type $(\alpha=-0.348, p<0.05)$, with attitude towards the male pill increasing by 0.348 points for individuals in stable relationships compared to individuals

Table 3 Predictors in multiple regression model of attitude towards the male pill

\begin{tabular}{lrrl}
\hline Predictor & $\boldsymbol{\beta}$ & $\boldsymbol{T}$ & $\boldsymbol{p}$ \\
\hline Gender & 0.737 & 5.341 & $0.000^{* \star * *}$ \\
Relationship type & -0.348 & -2.539 & $0.012^{*}$ \\
Trust in men's effective use of the male pill & 0.136 & 1.979 & $0.049^{*}$ \\
Reported health behaviours & 0.087 & 0.525 & 0.601 \\
Age & -0.005 & -0.538 & 0.591 \\
Self-efficacy & 0.228 & 1.226 & 0.222 \\
\hline
\end{tabular}

${ }^{*} p<0.05,{ }^{* \star * *} p<0.0001$. 
in casual relationships, and trust in men's effective use of the male pill $(\alpha=0.136, p<0.05)$, with attitude towards the male pill increasing by 0.136 points for every point increase in trust. Thus, being female and having trust in men's effective use of the male pill reliably predicted a positive attitude towards the male pill, while being male, being involved in casual sexual relationships or no relationship, and having low trust in its effective use by themselves reliably predicted a negative attitude.

\section{Discussion}

While men's trust in the effective use of MHC has not sufficiently been explored in the existing literature, previous findings on women's trust are mixed.4,5 The present study suggests that, in general, the effective use of the male pill is doubted more by females than males, although this lack of trust does not seem to have a significant impact on women's favourable attitudes. This apparent contradiction is intriguing, as it implies that neither the fear of potential adverse side effects nor a lack of trust in the ability to use MHC effectively act as significant barriers towards the acceptability of the male pill in females. One possible explanation might be that women, unlike men, have first-hand experience using hormonal contraception and may therefore have more realistic expectations of its effectiveness and ease of use.

In both sexes, high perceived self-efficacy was associated with reporting to engage in more health-related behaviours, and this association was stronger in women than in men. This finding supports other studies that also have reported a strong relationship between health-related behaviour and self-efficacy in both sexes 30,41 and in women specifically. ${ }^{42,43}$ The idea of men's concerns about side effects in relation to the use of the male pill was not supported in this sample, since expressed interest in a healthy body (by displaying healthy behaviours) did not relate to a negative attitude towards the male pill. More support was found for men's masculine role, in that those men not showing much interest in their health also did not show much interest in the availability of the male pill.

In particular, men who were in a stable sexual relationship had a more favourable attitude towards the male pill and showed more eagerness for its availability. This is in line with previous findings that condoms are preferred in casual sexual relationships, while the contraceptive pill is favoured in stable relationships. ${ }^{32,44}$ It thus appears as though the primary target group for MHC would be males in stable sexual relationships, but the results also imply that there is a need for these individuals' confidence in the effective use of MHC to be increased. It needs, however, to be acknowledged that the terms 'stable' and 'casual' may be understood differently in relationship to sexual partnerships. ${ }^{45}$ Future research would need to take this into account.

The best way of administering the male pill may vary with each individual. Just as female hormonal contraception exists in different presentations, some males may similarly prefer periodical injections, contraceptive patches or other presentations to a daily tablet. Ensuring that there are a variety of presentations available may boost women's confidence in their partner using MHC effectively.

This study used a self-administered questionnaire; future research may benefit from employing qualitative methods (e.g. semi-structured interviews or focus groups). Furthermore, other variables might have an impact, such as religious orientation and education, as well as variables related to contraceptive use (e.g. level of contraceptive experience). Additionally, future studies should aim for equal numbers of male and female participants to ensure a representative sample. A measure of refusal to take part should be included, in particular to examine whether men whom we might expect to avoid confrontation with contraceptive issues - are more likely to decline participation.

Women tend to come into contact with reproductive health services more than men do ${ }^{15,17}$ and consequently awareness and decision-making regarding MHC could partly be determined by the information that women receive from these services. Furthermore, this study highlights the important role that trust in effective use plays. Accordingly, it seems advisable to design promotional campaigns to not only encourage men to use MHC, but also to encourage women to discuss the male pill with their partner. This may provide a means of increasing its uptake, once such a contraceptive method is freely available.

\section{Statements on funding and competing interests \\ Funding None identified.}

Competing interests None identified.

\section{Editor's note}

Readers might like to refer to the Consumer Correspondent article on page 197 of this issue, which explores what women (and men) really want from their chosen contraceptive method.

\section{References}

1 Wang C, Swerdloff RS. Male hormonal contraception. Am J Obstet Gynecol 1994; 190: S60-S68.

2 Trussell J. Contraceptive efficacy. In: Hatcher RA, Trussell J, Nelson AL, Cates W, Stewart FH, Kowal D (eds), Contraceptive Technology (19th revised edn). New York, NY: Ardent Media, 2007.

3 Anderson RA, Baird DT. Male contraception. Endocr Rev 2002 ; 23: 735-762.

4 Marcell AV, Plowden RN, Bowman SM. Exploring older adolescents' and young adults' attitudes regarding male hormonal contraception: applications for clinical practice. Hum Reprod 2005; 20: 3078-3084.

5 Glasier AF, Anakwe R, Everington D, Martin CW, van der Spuy Z, Cheng L, et al. Would women trust their male partners to use a male pill? Hum Reprod 2000; 15: 637-645.

6 Potts M. The myth of the male pill. Nat Med 1996; 2: 398-399.

7 Gallen ME, Liskin L, Kak N. Men - new focus for family planning programs. Popul Rep J 1986; 33: J889-J919.

8 Yusuf F, Siedlecky S. Patterns of contraceptive use in Australia: analysis of the 2001 National Health Survey. J Biosoc Sci 2007; 39: 735-744.

9 Grady WR, Tanfer K, Billy JOG, Lincoln-Hanson J. Men's perceptions of their roles and responsibilities regarding sex, contraception and childrearing. Fam Plann Perspect 1996; 28: 221-226.

10 Ringheim K. Factors that determine prevalence of use of contraceptive methods for men. Stud Fam Plann 1993; 24 : 87-99.

11 Szasz I. Masculine identity and the meanings of sexuality: a review of research in Mexico. Reprod Health Matters 1998; 6: 97-104.

12 Figueroa-Perea JG. A gendered perspective on men's reproductive health. Int J Mens Health 2003; 2: 111-130.

13 Oudshoorn N. The Male Pill: A Biography of a Technology in the Making. Durham, NC: Duke University Press, 2003.

14 Oudshoorn N. "Astronauts in the Sperm World": the renegotiation of masculine identities in discourses on male contraceptives. Men and Masculinities 2004; 6: 349-367.

15 van Wersch A. Health and illness. In: Trew K, Kremer J (eds), Gender and Psychology. London, UK: Arnold Publishers, 1998; 167-179.

16 Department of Health. Health Minister to announce new plans to improve men's health. 29 March 2000. http://www.dh.gov.uk/ en/Publicationsandstatistics/Pressreleases/DH 4002600 [Accessed 12 January 2009].

17 Department of Health. NHS Contraceptive Services, England: 1997-98. http://www.dh.gov.uk/en/Publicationsandstatistics/ Statistics/StatisticalWorkAreas/Statisticalhealthcare/DH 4016 204 [Accessed 12 January 2009].

18 Glass D, Feldhahn S. Is male contraception a good idea? The Atlanta Journal-Constitution. 31 October 2003. http://www.ajc. com/opinion/contet/opinion/woman/1003/31.html [Accessed 12 January 2009]. 
19 Van Kammen J, Oudshoorn N. Gender and risk assessment in contraceptive technologies. Sociol Health IIIn 2002; 24: 436-461.

20 Oddens BJ, Visser AP, Vemer HM, Everaerd WT, Lehert, P. Contraceptive use and attitudes in Great Britain. Contraception 1994; 49: 73-86.

21 Rosenburg MJ, Waugh MS, Meehan TE. The use and misuse of oral contraceptives: risk indicators for poor pill taking and discontinuation. Contraception 1995; 51: 283-288.

22 Green CP, Cohen SI, Belhadj-El Ghouayel H. Male Involvement in Reproductive Health, Including Family Planning and Sexual Health (Technical Report 28, United Nations Population Fund). New York, NY: United Nations Population Fund, 1995.

23 Edwards SR. The role of men in contraceptive decisionmaking: current knowledge and future implications. Fam Plann Perspect 1994; 26: 77-82.

24 Henry J Kaiser Family Foundation The 1997 Kaiser Family Foundation Survey on Men's Role in Preventing Pregnancy. Menlo Park, CA: Henry J Kaiser Family Foundation, 1997.

25 Brooks M. Men's views on male hormonal contraception - a survey of the views of attenders at a fitness centre in Bristol. $\mathrm{Br}$ J Fam Plann 1998; 24: 7-17.

26 Weston GC, Schlipalius ML, Bhuinneain MN, Vollenhoven BJ. Will Australian men use hormonal contraception? A survey of a postpartum population. Med J Aust 2002; 176: 200-210.

27 Heinemann K, Saad F, Wiesemes M, White S, Heinemann L. Attitudes toward male fertility control: results of a multinational survey on four continents. Hum Reprod 2005; 20: 549-556.

28 O'Connor DB, Ferguson E, O'Connor RC. Intentions to use hormonal male contraception: the role of message framing, attitudes and stress appraisals. $\mathrm{Br} J$ Psychol 2005; 96: 351-369.

29 Reis TJ, Gerrard M, Gibbons FX. Social comparison and the pill: reactions to upward and downward comparison of contraceptive behavior. Pers Soc Psychol Bull 1993; 19: 13-20.

30 Schwarzer R, Fuchs R. Self-efficacy and health behaviours. In: Conner M, Norman P (eds), Predicting Health Behaviour: Research and Practice with Social Cognition Models. Buckingham, UK: Open University Press, 1995; 163-196.

31 Levinson RA. Teenage women and contraceptive behavior: focus on self-efficacy in sexual and contraceptive situations. Unpublished PhD thesis, Stanford University, Stanford, CA, USA, 1982

32 Landry DJ. Young unmarried men and women discuss men's role in contraceptive practice. Fam Plann Perspect 1994; 26: 222-227.

33 Brown JW, Villarruel AM, Oakley D, Eribes C. Exploring contraceptive pill taking among Hispanic women in the United States. Health Educ Behav 2003; 30: 663-682.

34 McCarraher DR, Martin SL, Bailey PE. The influence of method-related partner violence on covert pill use and pill discontinuation among women living in La Paz, El Alto and Santa Cruz, Bolivia. J Biosoc Sci 2006; 38: 169-186.

35 NCSS. Power Analysis and Sample Size Software (PASS). 2006. http://www.ncss.com/pass.html [Accessed 12 January 2009].

36 Prochaska TR, Leventhal EA, Leventhal H, Keller ML. Health practices and illness cognition in young, middle aged and elderly adults J Gerontol 1985; 40: 569-578.

37 Schwarzer R, Jerusalem M. Generalized Self-Efficacy Scale. In: Weinman J, Wright S, Johnson M (eds), Measures in Health Psychology: A User's Portfolio, Causal and Control Beliefs. Windsor, UK: NFER-Nelson, 1995; 35-37.

38 Booth-Kewley S, Vickers RR. Associations between major domains of personality and health behavior. J Pers 1994; 62: 281-298.

39 Schwarzer R. General Perceived Self-Efficacy Scale (GSE). http://userpage.fu-berlin.de/ health/selfscal.htm [Accessed 12 January 2009].

40 Field AP Discovering Statistics Using SPSS for Windows: Advanced Techniques for the Beginner. London, UK: Sage, 2000.

41 Schwarzer R, Schutz B, Ziegelmann JP, Lippke S, Luszczynska A, Scholz U. Adoption and maintenance of four health behaviors: theory-guided longitudinal studies on dental flossing, seat belt use, dietary behavior, and physical activity. Ann Behav Med 2007; 33: 156-166.

42 Chen C, Lee P, Chou Y, Kuo S, Hsu Y. Avoidance of environmental tobacco smoke among pregnant Taiwanese women: knowledge, self-efficacy, and behavior. $J$ Womens Health 2007; 16: 869-878.

43 Boer H, Mambasha MT. Gender power imbalance and differential psychosocial correlates of intended condom use among male and female adolescents from Venda, South Africa. Br J Health Psychol 2007; 12: 51-63.

44 Rossier $\mathrm{C}$, Leridon $\mathrm{H}$. The pill and the condom, substitution or association? An analysis of the contraceptive histories of young women in France, 1978-2000. Population 2004; 59: 387-414.

45 Buyss A. Safer sexual decision making in stable and casual relationships: a prototype approach. Psychol Health 1998; 13: 55-66.

\section{FACULTY OF SEXUAL \& REPRODUCTIVE HEALTHCARE MEMBERSHIP EXAMINATION}

The Membership Examination (MFSRH) consists of:

\section{- Part 1 Multiple Choice Question paper (MCQ)}

This 11/2-hour paper consists of 60 clinical science and applied science questions.

The examination date(s) for the London-based examination are still to be confirmed, but details will appear on the Faculty of Sexual and Reproductive Healthcare website in due course (www.fsrh.org).

\section{- Evidence Based Commentary (EBC)}

The Evidence Based Commentary replaces the case reports/dissertation component of the Membership examination and candidates can now view the first annually released topic on the Faculty website. Candidates have an absolute deadline of $\mathbf{3 1}$ August 2009 to submit the Commentary on this topic. The Commentary must be a minimum of 1000 words and a maximum of 2000 words, excluding references, tables and appendices, and the format must follow the guidance notes. Candidates can find detailed information in the Candidate Guidance Notes for Evidence Based Commentary and the Membership Examination Regulations (September 2008) on the Faculty website.

\section{Part 2 Examination (CRQ, SAQ, OSCE)}

This all-day examination consists of:

- Critical Reading Question examination paper (CRQ)

- Short Answer Question examination paper (SAQ)

- Objective Structured Clinical Examination (OSCE)

The Faculty must receive applications for the MFSRH Part 2 held in June 2010 by 3 January 2010. Information on the Part 2 examination, the Examination Regulations and the application form appear on the Faculty website.

The qualification is subject to re-certification every 5 years.

For the current MFSRH Examination Regulations (September 2008), information on all components of the MFSRH examination and application forms, please visit the FSRH website: www.fsrh.org (see Training \& Exams, Membership Exam) or e-mail Denise Pickford at denise@fsrh.org. 